\title{
A sudden stratospheric warming compendium
}

\author{
Amy H. Butler ${ }^{1,2}$, Jeremiah P. Sjoberg ${ }^{1,2}$, Dian J. Seidel ${ }^{3,}$, and Karen H. Rosenlof ${ }^{2}$ \\ ${ }^{1}$ Cooperative Institute for Research in Environmental Sciences, University of Colorado, Boulder, \\ CO 80309, USA \\ ${ }^{2}$ National Oceanic and Atmospheric Administration, Earth Systems Research Laboratory, \\ Chemical Sciences Division, Boulder, CO 80305, USA \\ ${ }^{3}$ National Oceanic and Atmospheric Administration, Air Resources Laboratory, College Park, MD 20740, USA \\ retired \\ Correspondence to: Amy H. Butler (amy.butler@noaa.gov)
}

Received: 23 September 2016 - Discussion started: 27 September 2016

Revised: 20 December 2016 - Accepted: 5 January 2017 - Published: 9 February 2017

\begin{abstract}
Major, sudden midwinter stratospheric warmings (SSWs) are large and rapid temperature increases in the winter polar stratosphere are associated with a complete reversal of the climatological westerly winds (i.e., the polar vortex). These extreme events can have substantial impacts on winter surface climate, including increased frequency of cold air outbreaks over North America and Eurasia and anomalous warming over Greenland and eastern Canada. Here we present a SSW Compendium (SSWC), a new database that documents the evolution of the stratosphere, troposphere, and surface conditions 60 days prior to and after SSWs for the period 1958-2014. The SSWC comprises data from six different reanalysis products: MERRA2 (1980-2014), JRA-55 (1958-2014), ERA-interim (1979-2014), ERA-40 (1958-2002), NOAA20CRv2c (1958-2011), and NCEP-NCAR I (19582014). Global gridded daily anomaly fields, full fields, and derived products are provided for each SSW event. The compendium will allow users to examine the structure and evolution of individual SSWs, and the variability among events and among reanalysis products. The SSWC is archived and maintained by NOAA's National Centers for Environmental Information (NCEI, doi:10.7289/V5NSORWP).
\end{abstract}

\section{Introduction}

The winter polar stratosphere is highly dynamic. In the Northern Hemisphere $(\mathrm{NH})$, breaking planetary-scale waves propagating up from the troposphere or the excitation of resonant modes can lead to the disruption and deceleration of the climatological westerly circulation of the polar vortex (see Schoeberl, 1978 for a historical review). Associated with this wind deceleration is a dramatic warming, sometimes increasing the temperature of the polar stratosphere by as much as $30-40 \mathrm{~K}$ in a few days. In the most extreme cases, the stratospheric polar vortex can reverse direction completely in an event called a major sudden stratospheric warming (SSW). SSWs in the NH occur roughly six times per decade (Charlton and Polvani, 2007). SSWs can also occur in the Southern Hemisphere (SH), as in a remarkable case in September 2002
(Kruger et al., 2005), but are rare due to smaller planetary wave amplitudes in the SH (van Loon et al., 1973).

Large perturbations in the stratospheric circulation can drive changes in surface climate for days to weeks (Kidston et al., 2015). In particular, SSWs are often followed by an equatorward shift of the North Atlantic tropospheric storm track, projecting onto the spatial pattern of the negative phase of the North Atlantic Oscillation (NAO). On average, this pattern results in warm anomalies over Greenland, eastern Canada, and subtropical Africa and Asia and cold anomalies over northern Eurasia and the eastern United States. However, the impacts of individual SSWs vary widely, depending on the evolution of the vortex breakdown, the strength of the stratospheric-tropospheric coupling, and the state of the tropospheric climate.

Because of the impact of SSWs on winter surface climate and midlatitude cold air outbreaks, as well as their poten- 
tial influence on ozone and chemical transport (e.g., Manney et al., 2009; Schoeberl and Hartmann, 1991), tropical convection and dynamics (e.g., Gómez-Escolar et al., 2014; Kodera, 2006), and mesospheric processes (e.g., Hoffmann et al., 2007), a research-ready database of these events would be useful. Daily three-dimensional gridded variables are needed to examine the full evolution and impacts of SSWs. Therefore, reanalysis products, which assimilate observations to constrain a global climate model, are often used. However, the calculation of daily anomalies or additional derived products using reanalysis data can be computationally expensive and storage intensive. In addition, different reanalyses also differ in time spans, assimilated observations, assimilation scheme, parameterizations, and model physics. This makes intercomparison of multiple reanalysis products useful for assessing what features of SSWs and their associated climate variability are robust.

Here we describe a SSW Compendium (SSWC), which provides a detailed historical dataset of major SSWs, allowing users to consider the development, evolution, and impacts of individual SSWs and to provide a basis for model evaluation and improvement. A compendium is a concise compilation of comprehensive information on a specific subject, and therefore is an appropriate term to describe this dataset. The SSWC includes data from six established reanalysis products and includes anomaly fields and additional derived products to highlight the dynamics and effects of SSW events. We present an overview of the reanalysis source data and the methodology for SSW event selection and data processing in Sect. 2. Section 3 discusses potential applications of this database, and Sect. 4 highlights the availability of the database at the National Oceanic and Atmospheric Administration (NOAA) National Centers for Environmental Information (NCEI) archives and at the NOAA Earth Systems Research Laboratory (ESRL).

\section{Methodology}

\subsection{Reanalysis data}

The SSWC comprises data from six different reanalyses (Table 1): the National Aeronautics and Space Administration (NASA) Modern-Era Retrospective-analysis for Research and Applications version 2 (MERRA2), Japanese 55-year Reanalysis (JRA-55), European Centre for Medium-Range Weather Forecasts (ECMWF) 40-year Reanalysis (ERA40), ECMWF Interim Reanalysis (ERA-interim), NOAA 20th Century Reanalysis version 2c (NOAA20CRv2c), and NOAA's National Centers for Environmental Prediction/National Center for Atmospheric Research (NCEPNCAR I) reanalysis.

Reanalyses are derived from observations from multiple sources (including surface observations, aircraft, radiosondes, rocketsondes, and satellites) that are assimilated by global coupled land-atmosphere-ocean models to cre- ate spatially and temporally complete observational records. There are advantages and disadvantages of using reanalysis products for this database, as opposed to individual measurement sources or various stratospheric analyses. These analyses include that from the Freie Universitat Berlin, which produces a database of continuous daily gridded synopticscale analyses based largely on radiosonde measurements, but only for three stratospheric levels for a 35-year period (Labitzke and Collaborators, 2002), and from the NOAA Climate Prediction Center (CPC), which offers analyzed stratospheric temperatures at eight stratospheric levels based on satellite retrievals of the advanced microwave sounding unit (AMSU). The major advantage of reanalysis is that it allows consideration of the evolution of SSWs and their impacts throughout the entire atmosphere with a spatial and temporal extent that is not feasible using individual measurements or stratospheric analyses alone. A major disadvantage of using reanalysis is that due to sparse observations, particularly in the pre-satellite era, stratospheric reanalysis is poorly constrained, especially above $10 \mathrm{hPa}$ (Manney et al., 2003), and tropospheric reanalysis may be poorly constrained over oceans and remote regions (e.g., Bosilovich et al., 2008). Reanalyses can also suffer from upper-boundary effects and discontinuities due to model streams or changes in the observations being assimilated (Fujiwara et al., 2016; Labitzke and Kunze, 2005). These issues should not have a strong effect on the daily-to-seasonal timescales documented in the SSWC, but should be kept in mind, especially for data above $10 \mathrm{hPa}$ where the discontinuities are conspicuous.

Some biases and uncertainties in individual reanalysis products have been documented (see references in Table 1), and an evaluation of their stratospheric processes is currently the focus of an international effort by the Stratospheretroposphere Processes And their Role in Climate (SPARC) Reanalysis Intercomparison Project (S-RIP; Fujiwara et al., 2016). While initial studies have shown that stratospheric dynamics and variability of and coupling to the surface are reasonably simulated in reanalyses (Martineau and Son, 2010), particularly in the latest generation products (Martineau et al., 2016), the SSWC enables quick comparison between reanalyses of sudden stratospheric warming events and their evolution on daily timescales. This capability is important when considering the substantial volume of data needed to calculate the daily climatology and anomalies for each grid point and pressure level in each reanalysis.

Certain reanalysis output provided in the SSWC should be used with caution. For example, we provide the reanalysis ozone mass mixing ratio and total column ozone output (where available) since there are interesting changes in ozone following a SSW event (e.g., Fig. 3). However, users should be aware that most reanalysis ozone fields are based on assimilated satellite measurements that utilize backscattered sunlight and cannot measure ozone during polar night. Reanalysis systems thus rely heavily on the model, which typically parameterizes heterogeneous chemistry, to simulate 
Table 1. The reanalyses included in the SSW Compendium.

\begin{tabular}{lllrrr}
\hline Reanalysis & $\begin{array}{l}\text { Time } \\
\text { period }\end{array}$ & Reference & $\begin{array}{r}\text { Native horizontal } \\
\text { resolution }\end{array}$ & $\begin{array}{r}\text { Vertical resolution } \\
\text { (model/pressure levels) }\end{array}$ & $\begin{array}{r}\text { Model } \\
\text { top }\end{array}$ \\
\hline ERA-40 & $1958-2002$ & Uppala et al. (2005) & $1.125^{\circ} \times 1.125^{\circ}$ & $60 / 23$ & $0.1 \mathrm{hPa}$ \\
ERA-interim & $1979-2014$ & Dee et al. (2011) & $0.75^{\circ} \times 0.75^{\circ}$ & $60 / 23$ & $0.1 \mathrm{hPa}$ \\
JRA-55 & $1958-2014$ & Kobayashi et al. (2015) & $1.25^{\circ} \times 1.25^{\circ}$ & $60 / 37$ & $0.1 \mathrm{hPa}$ \\
MERRA2 & $1980-2014$ & Molod et al. (2015) & $0.5^{\circ} \times 0.667^{\circ}$ & $72 / 42$ & $0.01 \mathrm{hPa}$ \\
NCEP-NCAR I & $1958-2014$ & Kalnay et al. (1996) & $2.5^{\circ} \times 2.5^{\circ}$ & $28 / 17$ & $3 \mathrm{hPa}$ \\
NOAA20CRv2c & $1958-2014$ & Compo et al. (2011) & $2^{\circ} \times 2^{\circ}$ & $28 / 24$ & $10 \mathrm{hPa}$ \\
\hline
\end{tabular}

ozone at high latitudes, leading to potentially high errors (Dethof and Hólm, 2004; Dragani, 2011).

In addition, the evolution of SSW events prior to 1964, when concentrated efforts to observe the upper atmosphere using radiosondes and rocketsondes were begun in association with the International Years of the Quiet Sun (IQSY), should be viewed with skepticism. Even radiosonde measurements of the stratosphere were very limited during that time period, and so reanalysis fields may be almost entirely model-driven.

The NOAA20CRv2c is unique among the reanalyses, because it assimilates only surface pressure observations. Thus, the stratosphere is not constrained by any stratospheric observations, and the reanalysis winds are not realistic (Compo et al., 2011). However, because surface pressure observations do a reasonable job of constraining the model throughout the northern hemispheric troposphere (Compo et al., 2011), we include the NOAA20CRv2c to examine the tropospheric impacts of SSWs, using SSW event dates given by the JRA55 reanalysis (Table 2 ). The NOAA20CRv2c reanalysis provides the unique opportunity to examine tropospheric and stratospheric interaction prior to and following SSWs, when only the surface is constrained by observations.

\subsection{Event selection}

Major SSWs occur when the winter polar stratospheric westerlies reverse to easterlies. In minor warmings, the polar temperature gradient reverses but the circulation does not, and in final warmings, the vortex breaks down and remains easterly until the following boreal autumn. Because no unambiguous standard definition for major, minor, and final warmings yet exists (Butler et al., 2015), selecting SSW events to include in the Compendium is not straightforward.

The primary goal of the SSWC is to provide data for major SSWs, which have been found to have the largest surface impacts (Palmeiro et al., 2015). We recognize that any criteria we use may also select marginal events or miss events that perhaps should be considered major in terms of surface influences. We employ the following simple, commonly used definition for major warmings (Charlton and Polvani 2007; hereafter CP07): the central date or event date of a SSW occurs when the daily-mean zonal-mean zonal winds at $10 \mathrm{hPa}$ and $60^{\circ} \mathrm{N}$ first change from westerly to easterly between November and March. The winds must return to westerly for 20 consecutive days between events (to avoid counting the same event twice, roughly equivalent to the thermal damping timescale at $10 \mathrm{hPa}$; Newman and Rosenfield, 1997). If the winds do not return to westerly for at least 10 consecutive days before 30 April, the warming is a final warming and is not included. The central dates for major NH SSWs in each reanalysis are provided in Table 2 . We include in the SSW Compendium, for each reanalysis, every event detected in any reanalysis and shown in Table 2 (for example, we include data for the 30 November 1958 event for all reanalyses extending back to 1958, even though it was only detected in NCEP-NCAR). This includes the NOAA20CRv2c, even though that reanalysis detects only a single event.

There are two main types of SSW: displacement events in which the stratospheric polar vortex is displaced from the pole and split events in which the vortex splits into two or more vortices (Fig. 1). Some SSWs are a combination of both types. There are a number of methods for determining the type of SSW. We do not attempt to classify event types here; however, we do provide the filtered (and unfiltered) absolute vorticity field at $10 \mathrm{hPa}$ (see Sect. 2.3), which may enable classification of split-type SSWs according to the CP07 definition, in which the edges of the vortex are identified by the location of the maximum absolute vorticity gradient. We also provide potential vorticity (PV) interpolated onto isentropic surfaces, and geopotential heights at $10 \mathrm{hPa}$, both of which can be used to assess vortex moment diagnostics and determine the SSW type (Mitchell et al., 2011; Seviour et al., 2013; Waugh, 1997). We note that the vortex moment diagnostics detect some different dates of SSWs compared to CP07 (and these events are not included in the Compendium), but the provided data would allow classification of the included events.

While almost all SSWs occur in the $\mathrm{NH}$, we did examine their occurrence in the SH in the reanalyses (Table 3). The relevant dates for zonal-mean zonal wind reversals at $10 \mathrm{hPa}$ and $60^{\circ} \mathrm{S}$ were between July and October, and the winds must return to westerly for at least 10 consecutive days before 30 November. Keeping in mind that prior to 1979 there were hardly any observations of the SH polar stratosphere, 
Table 2. The central dates of NH SSWs detected in each reanalysis product ${ }^{\mathrm{a}}$. Empty cells indicate that no data are available; stars indicate that data are available but no SSW was detected.

\begin{tabular}{|c|c|c|c|c|c|c|}
\hline & ERA-40 & ERA-interim & JRA-55 & MERRA2 & NCEP-NCAR I & NOAA20CR \\
\hline 1 & 31-Jan-58 & & 30-Jan-58 & & 30-Jan-58 & $* * * *$ \\
\hline 2 & $* * * *$ & & $* * * *$ & & $30-N o v-58$ & $* * * *$ \\
\hline 3 & 17-Jan-60 & & 17-Jan-60 & & 16-Jan-60 & $* * * *$ \\
\hline 4 & 28-Jan-63 & & 30-Jan-63 & & $* * * *$ & $* * * *$ \\
\hline 5 & $* * * *$ & & $* * * *$ & & 23-Mar-65 & $* * * *$ \\
\hline 6 & 16-Dec-65 & & 18-Dec-65 & & 8-Dec-65 & $* * * *$ \\
\hline 7 & 23-Feb-66 & & 23-Feb-66 & & 24-Feb-66 & $* * * *$ \\
\hline 8 & 7-Jan-68 & & 7-Jan-68 & & $* * * *$ & $* * * *$ \\
\hline 9 & 28-Nov-68 & & 29-Nov-68 & & 27-Nov-68 & $* * * *$ \\
\hline 10 & 13-Mar-69 & & $* * * *$ & & 13-Mar-69 & $* * * *$ \\
\hline 11 & 2-Jan-70 & & 2-Jan-70 & & 2-Jan-70 & $* * * *$ \\
\hline 12 & 18-Jan-71 & & 18-Jan-71 & & 17-Jan-71 & $* * * *$ \\
\hline 13 & 20-Mar-71 & & 20-Mar-71 & & 20-Mar-71 & $* * * *$ \\
\hline 14 & 31-Jan-73 & & 31-Jan-73 & & 2-Feb-73 & $* * * *$ \\
\hline 15 & 9-Jan-77 & & 9-Jan-77 & & $* * * *$ & $* * * *$ \\
\hline 16 & 22-Feb-79 & 22-Feb-79 & 22-Feb-79 & & 22-Feb-79 & $* * * *$ \\
\hline 17 & 29-Feb-80 & 29-Feb-80 & 29-Feb-80 & 29-Feb-80 & 29-Feb-80 & 18-Mar-80 \\
\hline 18 & $* * * *$ & $* * * *$ & 6-Feb-81 & $* * * *$ & $* * * *$ & $* * * *$ \\
\hline 19 & 4-Mar-81 & 4-Mar-81 & 4-Mar-81 & $* * * *$ & $* * * *$ & $* * * *$ \\
\hline 20 & 4-Dec-81 & 4-Dec-81 & 4-Dec-81 & 4-Dec-81 & 4-Dec-81 & $* * * *$ \\
\hline 21 & 24-Feb-84 & $24-F e b-84$ & $24-F e b-84$ & $24-F e b-84$ & $24-F e b-84$ & $* * * *$ \\
\hline 22 & 1-Jan-85 & 1-Jan-85 & 1-Jan-85 & 1-Jan-85 & 2-Jan-85 & $* * * *$ \\
\hline 23 & 23-Jan-87 & 23-Jan-87 & 23-Jan-87 & 23-Jan87 & 23-Jan-87 & $* * * *$ \\
\hline 24 & 8-Dec-87 & 8-Dec-87 & 8-Dec-87 & 8-Dec-87 & 8-Dec-87 & $* * * *$ \\
\hline 25 & 14-Mar-88 & 14-Mar-88 & 14-Mar-88 & $14-M a r-88$ & 14-Mar-88 & $* * * *$ \\
\hline 26 & $21-F e b-89$ & $21-F e b-89$ & $21-F e b-89$ & $21-F e b-89$ & $22-F e b-89$ & $* * * *$ \\
\hline 27 & 15-Dec-98 & 15-Dec-98 & 15-Dec-98 & 15-Dec-98 & 15-Dec-98 & $* * * *$ \\
\hline 28 & 26-Feb-99 & 26-Feb-99 & 26-Feb-99 & 26-Feb-99 & 25-Feb-99 & $* * * *$ \\
\hline 29 & 20-Mar-00 & 20-Mar-00 & 20-Mar-00 & 20-Mar-00 & 20-Mar-00 & $* * * *$ \\
\hline 30 & 11-Feb-01 & 11-Feb-01 & 11-Feb-01 & 11-Feb-01 & 11-Feb-01 & $* * * *$ \\
\hline 31 & 31-Dec-01 & 30-Dec-01 & 31-Dec-01 & 30-Dec-01 & 2-Jan-02 & $* * * *$ \\
\hline 32 & 18-Feb-02 & $* * * *$ & $* * * *$ & $17-F e b-02$ & $* * * *$ & $* * * *$ \\
\hline 33 & & 18-Jan-03 & 18-Jan-03 & 18-Jan-03 & 18-Jan-03 & $* * * *$ \\
\hline 34 & & 5-Jan-04 & 5-Jan-04 & 5-Jan-04 & 7-Jan-04 & $* * * *$ \\
\hline 35 & & 21-Jan-06 & 21-Jan-06 & 21-Jan-06 & 21-Jan-06 & $* * * *$ \\
\hline 36 & & $24-F e b-07$ & $24-F e b-07$ & $24-F e b-07$ & $24-F e b-07$ & $* * * *$ \\
\hline 37 & & 22-Feb-08 & 22-Feb-08 & $22-F e b-08$ & $22-F e b-08$ & $* * * *$ \\
\hline 38 & & 24-Jan-09 & 24-Jan-09 & 24-Jan-09 & 24-Jan-09 & $* * * *$ \\
\hline 39 & & 9-Feb-10 & 9-Feb-10 & 9-Feb-10 & 9-Feb-10 & $* * * *$ \\
\hline 40 & & 24-Mar-10 & 24-Mar-10 & 24-Mar-10 & 24-Mar-10 & $* * * *$ \\
\hline 41 & & 06-Jan-13 & 07-Jan-13 & 06-Jan-13 & 07-Jan-13 & $* * * *$ \\
\hline
\end{tabular}

a These are the detected events in each reanalysis, but in the SSWC we provide data for all dates shown in this table for all reanalyses.

making reanalyses highly unconstrained, the only event detected occurred in September 2002. This event is included in the SSWC.

\subsection{Data processing}

The production flowchart for the SSWC is shown in Fig. 2. We obtained the native horizontal and vertical pressure-level data for each reanalysis from various research data archives:
NOAA20CRv2c and NCEP/NCAR I from the NOAA Earth System Research Laboratory, Physical Sciences Division (http://www.esrl.noaa.gov/psd/data/gridded/); JRA-55, ERA-interim, and ERA-40 from the University Corporation for Atmospheric Research (UCAR) Research Data Archive (http://rda.ucar.edu/); and MERRA-2 from the Modeling and Assimilation Data and Information Services Center (MDISC, http://disc.sci.gsfc.nasa.gov/mdisc/). 

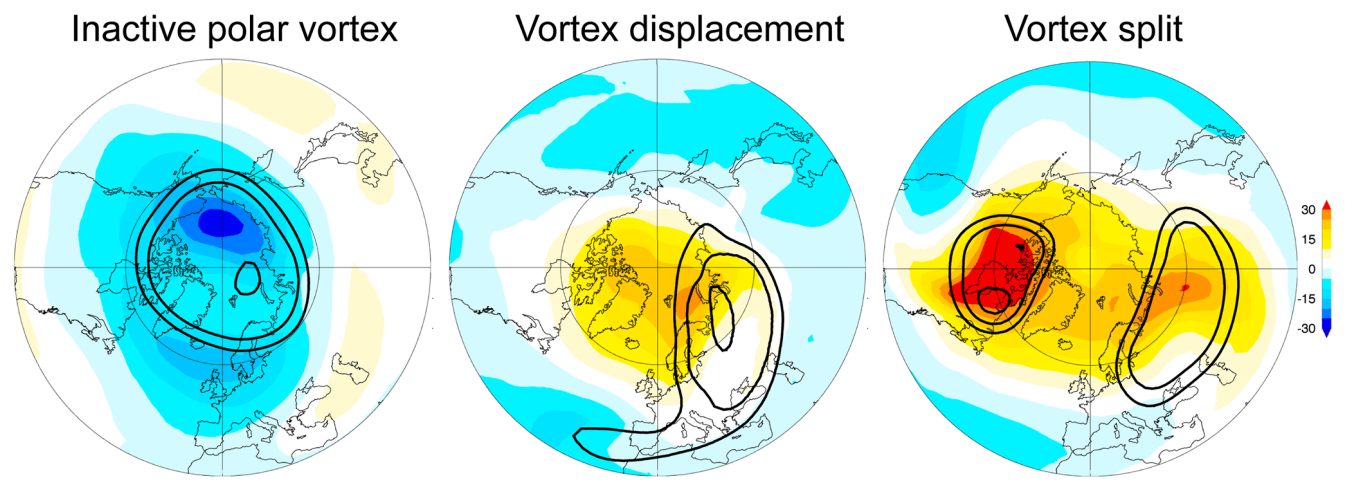

Figure 1. Temperature anomalies at $10 \mathrm{hPa}$ (shading, $(\mathrm{K})$ ) and the potential vorticity at $550 \mathrm{~K}$ (contours shown for 75,100 , and $125 \mathrm{PV}$ units) during (left) an inactive (or strong) phase of the polar vortex ( 9 January 2009), (center) a vortex displacement following the 23 January 1987 event, and (right) a vortex split following the 24 January 2009 event. MERRA2 reanalysis is used.

We extracted the following fields (when available): vertically integrated total column ozone; zonal winds, meridional winds, temperatures, geopotential heights, Ertel's potential vorticity (PV), and ozone mixing ratio, on provided pressure levels; and at the surface, mean daily temperature, minimum daily temperature, maximum daily temperature, mean sea level pressure, surface pressure, total precipitation liquid water equivalent, and total snowfall liquid water equivalent. Most raw reanalysis output is available every $6 \mathrm{~h}$ (for pressure-level fields) and sometimes up to every $3 \mathrm{~h}$ (for surface-level fields), but we computed daily means of all fields for the SSWC. We interpolated pressure-level fields onto a $2.5^{\circ} \times 2.5^{\circ}$ latitude-longitude grid, while the surfacelevel fields are maintained at native horizontal resolution. We retained data on provided pressure levels, but we interpolated certain fields (PV and ozone mixing ratio) onto isentropic surfaces. Unless isentropic-level data are provided, we calculated potential temperature $(\theta)$ from temperature data on pressure levels using Eq. (1):

$\Theta=T\left(\frac{p_{0}}{p}\right)^{R / C_{p}}$,

where $T$ and $p$ are atmospheric temperature and pressure, respectively, $p_{0}$ is a reference pressure defined as $1000 \mathrm{hPa}, R$ is the molar gas constant $\left(287 \mathrm{~J} \mathrm{deg}^{-1} \mathrm{~kg}^{-1}\right)$, and $c_{p}$ is the specific heat capacity at constant pressure $\left(1004 \mathrm{~J} \mathrm{deg}^{-1} \mathrm{~kg}^{-1}\right)$. The data, either on pressure or isentropic levels, are linearly interpolated at each time step onto 10 common isentropes $(330,350,400,450,500,550,600$, $700,850$, and $1000 \mathrm{~K})$. Note that in JRA-55, isentropic-level data are provided but not at the $1000 \mathrm{~K}$ surface; therefore, in the SSWC missing values are indicated for this theta level.

There are two types of output provided by the SSWC: climatological statistics and event-based data. Climatological statistic files include the mean and standard deviations of all output fields and percentiles from the climatological distribution for a selection of surface fields: minimum and maxi- mum surface temperature and precipitation. The climatological statistics are defined at each spatial point for 366 days spanning 1 July-30 June. The climatological mean is based on the entire time period of each reanalysis (Table 1). To calculate the climatological mean, we first calculate the mean of each day of the year over the full record. Then we calculate the Fourier transform of this daily mean climatology and retain the first four harmonics of the Fourier series (e.g., Wilks, 2006). This methodology smooths out the raw daily climatology while preserving low-frequency variability. The standard deviation is then calculated by taking the square root of the squared deviations in the raw daily data from this smoothed climatological mean. Percentiles are calculated following a method described in Zhang et al. (2005; see Eq. 1). Chosen percentiles are $5,10,90$, and $95 \%$. These statistics are calculated using the entire data record.

Event-based files contain full field, anomaly, and derived fields for the 60 days prior to and following each SSW event in Tables 2 and 3. Anomalies are calculated using the smoothed climatology for each field, using the entire data record for each reanalysis. We caution that, while the climatologies for different time periods are generally quite similar, using different periods for the climatology for each reanalysis means that differences in reanalysis anomaly fields may partially be a result of the climatology chosen. In addition to full fields and anomalies, we derive a number of useful diagnostics for understanding dynamic processes and surface climate surrounding SSW events, as described below:

1. We provide the maximum and minimum daily temperatures. NCEP-NCAR I provides this output; we calculate these values for the other reanalyses. Note that no interpolation is used - just the minimum and maximum values of the 3 or 6 hourly data - so these values may underestimate the true maximum and minimum daily temperatures.

2. We provide standardized geopotential height anomalies. The geopotential heights are standardized by subtract- 
Table 3. The central dates of the SH SSW detected in each reanalysis product.

\begin{tabular}{|c|c|c|c|c|c|}
\hline ERA-40 & ERA-interim & JRA-55 & MERRA2 & NCEP-NCAR I & NOAA20CR \\
\hline 1 & 25-Sep-02 & 26-Sep-02 & 26-Sep-02 & 26-Sep-02 & $* * * *$ \\
\hline
\end{tabular}

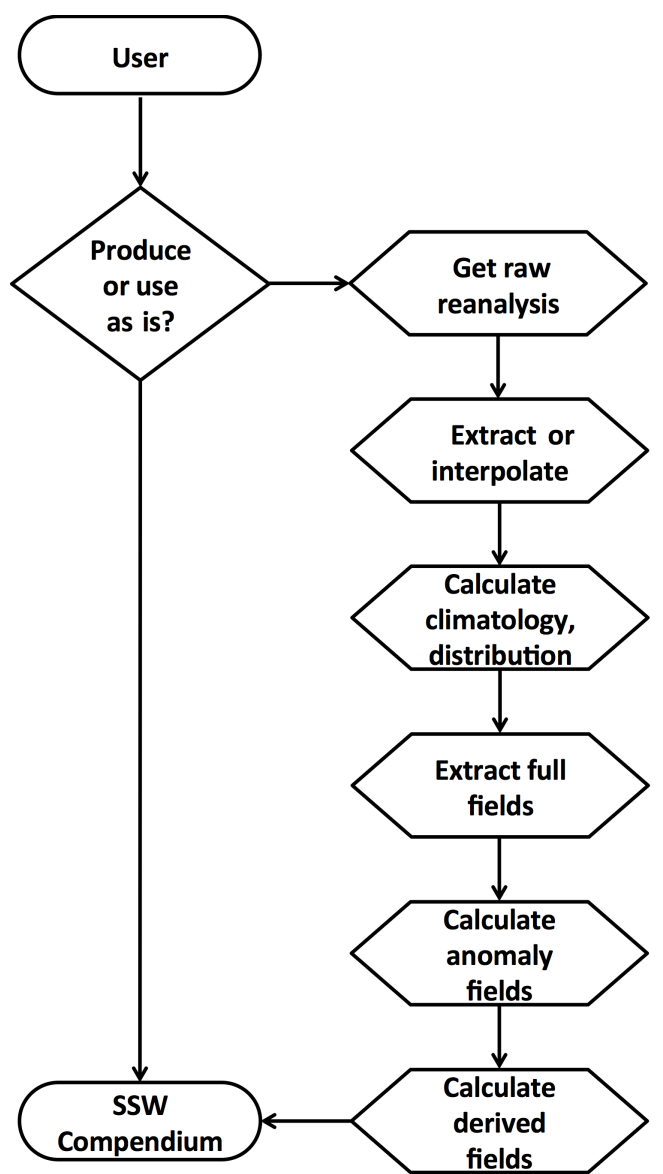

Figure 2. Flowchart showing how the SSWC can be used as is or the different steps to produce the dataset.

ing the mean and dividing by the standard deviation for the particular day of year and grid point.

3. We provide absolute vorticity $\left(\omega_{\mathrm{a}}\right)$ at $10 \mathrm{hPa}$. This is calculated from the $2.5^{\circ} \times 2.5^{\circ}$ gridded zonal and meridional wind fields using the vorticity equation in spherical coordinates:

$\omega_{\mathrm{a}}=\zeta+f=\left(\frac{1}{a} \frac{\partial v}{\partial \lambda}-\frac{1}{a \cos \phi} \frac{\partial(u \cos \phi)}{\partial \phi}\right)+f$,

where $\zeta$ is relative vorticity (defined by the parenthetical terms on the right-most side of the equation), $f$ is the Coriolis force $(2 \Omega \sin \phi), a$ is the Earth's radius, $\phi$ is the latitude in radians, $\lambda$ is the longitude in radians, $u$ is the zonal wind, and $v$ is the meridional wind.
4. We provide filtered absolute vorticity at $10 \mathrm{hPa}$. Here the absolute vorticity has been subject to a spherical smoothing procedure, in which the absolute vorticity is transformed into spherical harmonic space and subsequently transformed back while retaining only the first 11 harmonic coefficients. This filtering is part of CP07's event-type determination algorithm.

5. We provide zonal-mean eddy meridional heat flux $\left(v^{\prime} T^{\prime}\right)$, and its wave-number 1 and 2 components, as a function of pressure level and latitude. Here the primes $(')$ indicate deviations from the zonal mean. These are calculated using daily data. The wave-number components are found by applying a Fourier transform to the longitude dimension.

6. We provide zonal-mean eddy meridional momentum flux $\left(u^{\prime} v^{\prime}\right)$, and its wave-number 1 and 2 components, as a function of pressure level and latitude.

7. We provide the Northern Annular Mode (NAM) and the Southern Annular Mode (SAM) indices. The NAM or SAM patterns are calculated as the first empirical orthogonal function (EOF) of daily-mean zonal-mean geopotential height anomalies from 20 to $90^{\circ} \mathrm{N}$ or S. The NAM or SAM indices are the principal component time series corresponding to the first EOF for each hemisphere (Baldwin and Thompson, 2009). In the stratosphere, the annular mode is related to the strength of the polar vortex; in the troposphere, the annular mode is related to shifts in the tropospheric storm tracks (Gerber et al., 2012; Thompson et al., 2000).

8. We provide extreme events. For each grid space, either a 0 or 1 is given if the daily precipitation, minimum temperature, or maximum temperature anomaly exceeds a certain threshold. For precipitation, the anomaly must exceed the 95th percentile. Temperature anomalies must either be less than the 5 th or 10th percentile or greater than the 90th or 95 th percentile.

9. We provide time series of the location of maximum stratospheric warming within the region of $30-90^{\circ}$ latitude and between 300 to $1 \mathrm{hPa}$ (or as high as the reanalysis provides). This includes the geopotential height, latitude, longitude, and pressure of the maximum temperature anomaly. Time series of the location of the minimum zonal wind anomaly are also included for the same region. 
10. We provide time from the SSW event at which the zonal-mean zonal wind becomes easterly, as a function of pressure and latitude.

11. We provide pressure level at which the zonal-mean zonal wind becomes easterly, as a function of time and latitude.

Finally, a number of climate indices based on independent observations (not reanalysis data) have been included to provide a sense of other sources of climate variability that may be contributing to both the forcing of individual SSWs and the surface climate impacts. These include

1. measures of the phase of the El Niño-Southern Oscillation (ENSO). These indices allow the user to assess the state of the tropical Pacific, which has important winter effects on midlatitude climate. SSWs have been found to occur in $80 \%$ of El Niño winters (Butler and Polvani, 2011) and may modify the El Niño teleconnections when they occur (Butler et al., 2014; Richter et al., 2015). The Multivariate ENSO Index (MEI) is calculated as the first principal component of six different observed variables combined. The MEI data are from NOAA Physical Sciences Division (PSD): http://www.esrl.noaa.gov/psd/enso/mei/table.html. In addition to the MEI, we also provide the Oceanic Niño Index (ONI) and the Southern Oscillation Index (SOI). The ONI is calculated as the 3-month running mean of sea surface temperature anomalies in the Niño 3.4 region, based on a centered 30 -year base period updated every 5 years. The ONI data are from the NOAA CPC: http://www.cpc.ncep.noaa.gov/products/ analysis_monitoring/ensostuff/detrend.nino34.ascii.txt. The SOI is calculated as the difference between the standardized sea level pressure at Tahiti and Darwin. The SOI data are from the NOAA CPC: http://www.cpc.ncep.noaa.gov/data/indices/soi. All of these indices have been linearly interpolated from monthly data to daily data, assuming the monthly values are centered on the 15 th of the month;

2. the outgoing long-wave radiation Madden-Julian Oscillation (MJO) Index (OMI) amplitude and phase. SSWs may be related to the anomalous convection generated by the MJO during certain phases (e.g., Garfinkel et al., 2014). The OMI daily data are from NOAA PSD: http: //www.esrl.noaa.gov/psd/mjo/mjoindex/omi.1x.txt;

3 . the equatorial zonal winds measured by radiosondes near the equator, provided at $10,30,50$, and $70 \mathrm{hPa}$, as a measure of the Quasi-Biennial Oscillation (QBO). The QBO is thought to modulate the frequency of SSWs via changes in wave propagation (Baldwin et al., 2001; Dunkerton et al., 1988), perhaps in relation to the solar cycle (Labitzke et al., 2006). The QBO data are provided by Freie Universitat of Berlin: http://www.geo. fu-berlin.de/en/met/ag/strat/produkte/qbo/. These have been linearly interpolated from monthly data to daily data.

We acknowledge that other variables and indices may be useful for examining SSW dynamics, such as the Eliassen-Palm flux vector components or transformed Eulerian-mean diagnostics. Some of these diagnostics could be calculated using the provided daily data on pressure levels, though this may be imprecise relative to calculations on native model levels. Model-level data are often used for analyzing transport and processes near the tropopause, where vertical resolution on provided pressure levels may be inadequate or may introduce interpolation errors. Regardless, the SSWC is useful for a wide range of applications, as featured in the next section.

\section{Applications}

Here we highlight three types of potential applications of the SSWC: (i) composite analysis, (ii) individual event analysis, and (iii) reanalysis intercomparison.

\subsection{Composite analysis}

Assessing the composite response to SSWs is useful for separating the signals from internal noise and identifying where the signal is robust. Figure 3 shows, as a function of pressure level and time before and after the event, (a) zonal-mean zonal winds at $60^{\circ} \mathrm{N}$ and zonal-mean temperature anomalies averaged from 50 to $90^{\circ} \mathrm{N}$, (b) the Northern Annular Mode index at each pressure level, and (c) ozone mixing ratios from 60 to $90^{\circ} \mathrm{N}$, composited over all 41 northern hemispheric SSW events (Table 2), using the JRA-55 reanalysis. Figure 4 shows the surface response composited over the 60 days following the central date of all SSWs, including (a) mean sea level pressure anomalies, (b) surface temperature anomalies, and (c) precipitation anomalies.

These two figures illustrate several important and wellknown features of SSWs and their impacts on circulation and surface climate (e.g., Baldwin and Dunkerton, 2001). In the stratosphere, the zonal-mean zonal winds change from westerly to easterly at $10 \mathrm{hPa}$ and $60^{\circ} \mathrm{N}$ at lag zero (the central date), as constructed by the SSW definition (Fig. 3a). The zonal wind reversal is strongest near $\sim 3 \mathrm{hPa}$. In the composite, a complete wind reversal extends from $1 \mathrm{hPa}$ down to $\sim 10 \mathrm{hPa}$, but a deceleration of the zonal winds extends throughout the whole stratosphere. The peak warming of the stratosphere occurs $\sim 1$ day before the peak zonal wind reversal, and its location at $\sim 7 \mathrm{hPa}$ is consistent with peak zonal wind decreases at higher altitudes, per the thermal wind relationship. At $10 \mathrm{hPa}$ and higher, the zonal winds and temperatures rebound quickly after the SSW, reforming a colder westerly vortex above $10 \mathrm{hPa}$ after $10-15$ days. In the lower stratosphere, warmer, weaker vortex conditions persist 60 days following the SSW due to slow radiative 


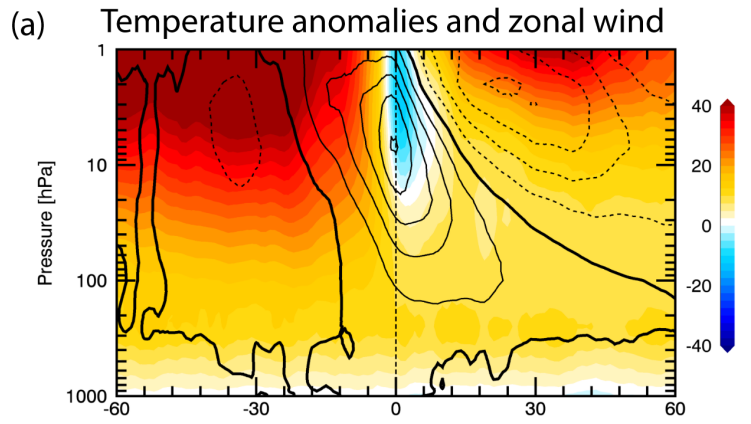

(b) Northern Annular Mode index

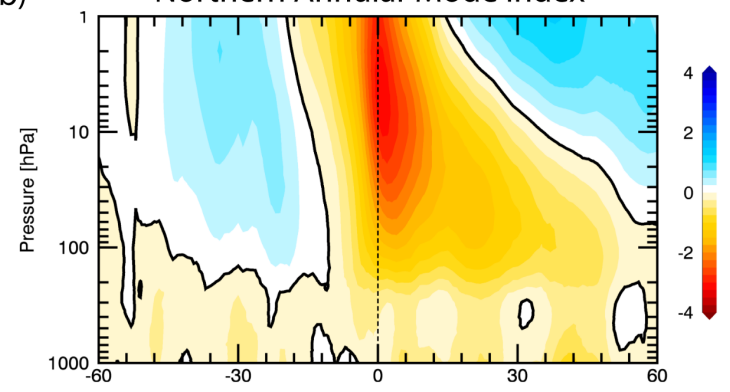

(c)

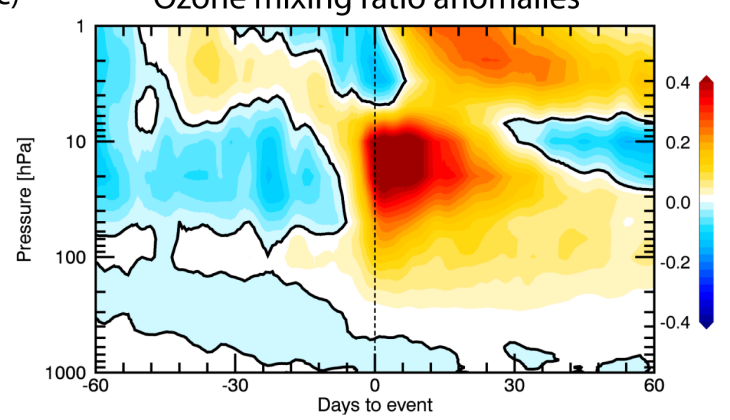

Figure 3. Composites of the 60 days before and after historical SSWs in the JRA-55 reanalysis for (a) temperature anomalies averaged from $50-90^{\circ} \mathrm{N}$ (contour levels are $2 \mathrm{~K}$, bold line is $0 \mathrm{~K}$ ) and zonal-mean zonal winds at $60^{\circ} \mathrm{N}$ (shading, $\left(\mathrm{m} \mathrm{s}^{-1}\right)$ ), (b) the Northern Annular Mode (NAM) index (stdevs), and (c) ozone mass mixing ratio anomalies from 60 to $90^{\circ} \mathrm{N}$ (ppmv).

timescales (Newman and Rosenfield, 1997). These changes near the tropopause may increase the persistence of the negative NAM phase in the troposphere (Fig. 3b), potentially providing a source of predictive skill for up to 60 days after the occurrence of the SSW (Maycock and Hitchcock, 2015). Following the SSW, the stratospheric ozone over the polar cap is greatly enhanced (Fig. 3c), both due to the increased transport of ozone-rich air into the stratosphere via the residual mean circulation and the horizontal mixing of high-ozone air into the region as the low-ozone region of the polar vortex is moved off the pole (either in one or two lobes, depending on whether a split- or displacement-type event has occurred).

At the surface, the composite response in mean sea level pressure anomalies comprises an anomalous high over the polar cap and Greenland and an anomalous low over the
North Atlantic, a pattern that projects well onto the negative phase of the NAO, the regional equivalent of the NAM (Fig. 4a). The associated surface temperature anomalies include significant warming over western Greenland and eastern Canada and strong cold air outbreaks over much of northern Europe, Asia, and the eastern United States (Fig. 4b). Conditions are also anomalously wet over western and central Europe and dry over Scandinavia (Fig. 4c).

Composite analysis could also be used to consider differences in SSW evolution and impacts in relation to other factors, such as the differences between split- and displacementtype events, the differences between events that occur in $\mathrm{El}$ Niño or La Niña winters, or the different phases of the MJO. Figure 5 highlights the differences in the evolution of the $500 \mathrm{hPa}$ geopotential height anomalies prior to and after a SSW during La Niña versus El Niño winters. Here we use the December-January-February ONI index to classify El Niño and La Niña years, with winters with ONI exceeding $+0.5^{\circ} \mathrm{C}$ defined as El Niño years and winters with ONI below $-0.5^{\circ} \mathrm{C}$ defined as La Niña years. While the sample size for these composites is small (13 events during El Niño years, 9 events during La Niña years), some major features are apparent; for example, the trough during El Niño and the ridge during La Niña in the North Pacific are evident throughout the evolution of the SSW. Note, however, the intensification of low-pressure anomalies in the northwest Pacific in the 60 days prior to SSWs in both El Niño and La Niña winters, a feature theorized in Garfinkel et al. (2012) to amplify planetary-scale waves from the troposphere into the stratosphere and weaken the stratospheric polar vortex. During El Niño winters, the tropospheric circulation pattern is strongest over North America in the days prior to a SSW, but strongest over the North Atlantic after a SSW. During La Niña winters, the anomalies over Greenland and Europe change sign before and after a SSW event, demonstrating the role of SSWs in winter climate over the North Atlantic-European region.

\subsection{Individual event analysis}

While compositing is useful for highlighting robust features of SSWs, the dynamic evolution and surface climate anomalies before and after each individual SSW can vary widely. The SSWC can be used to demonstrate this range of variability. Figure 6 illustrates the differences in the tropospheric climate following two similar split-type SSWs, one in January 1985 and the other in January 2009. In both events, the polar vortex split into two lobes: the one associated with the greatest warming anomalies centered over Canada and the other centered over northern Europe and Asia (Fig. 6a, b). The 2009 split SSW had a larger lobe that extended over most of Eurasia, but otherwise the stratospheric evolution was quite similar.

However, the subsequent surface and tropospheric responses in the weeks following the events differed in several ways. The $500 \mathrm{hPa}$ height anomaly pattern following 


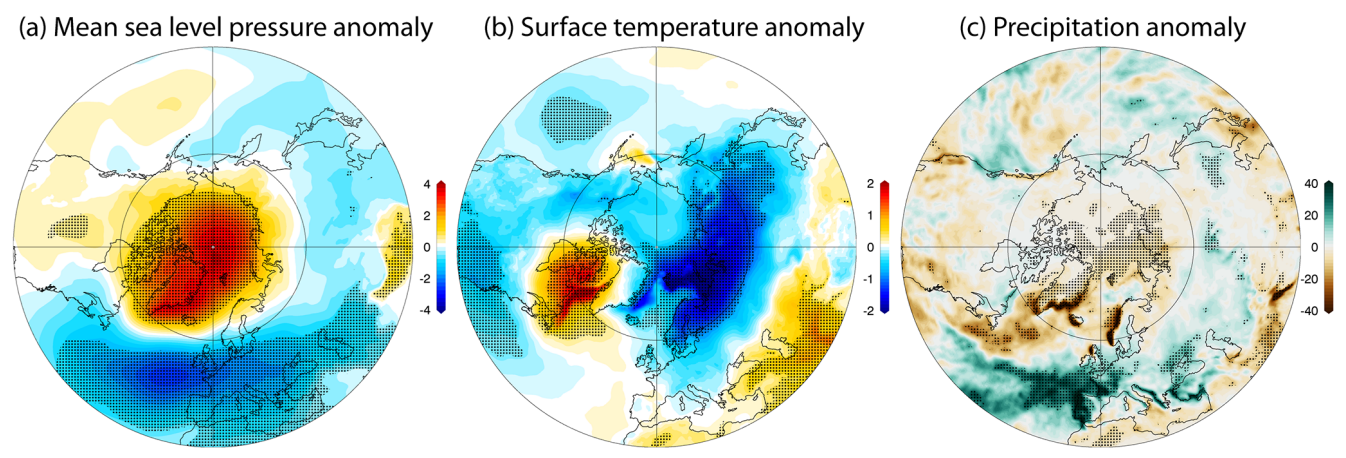

Figure 4. Composites of the 60 days after historical SSWs in the JRA-55 reanalysis for (a) mean sea level pressure anomalies (hPa), (b) surface temperature anomalies (K), and (c) precipitation anomalies ( $\mathrm{mm}$ ). The stippling indicates regions that are significantly different from the climatology at the $95 \%$ level.

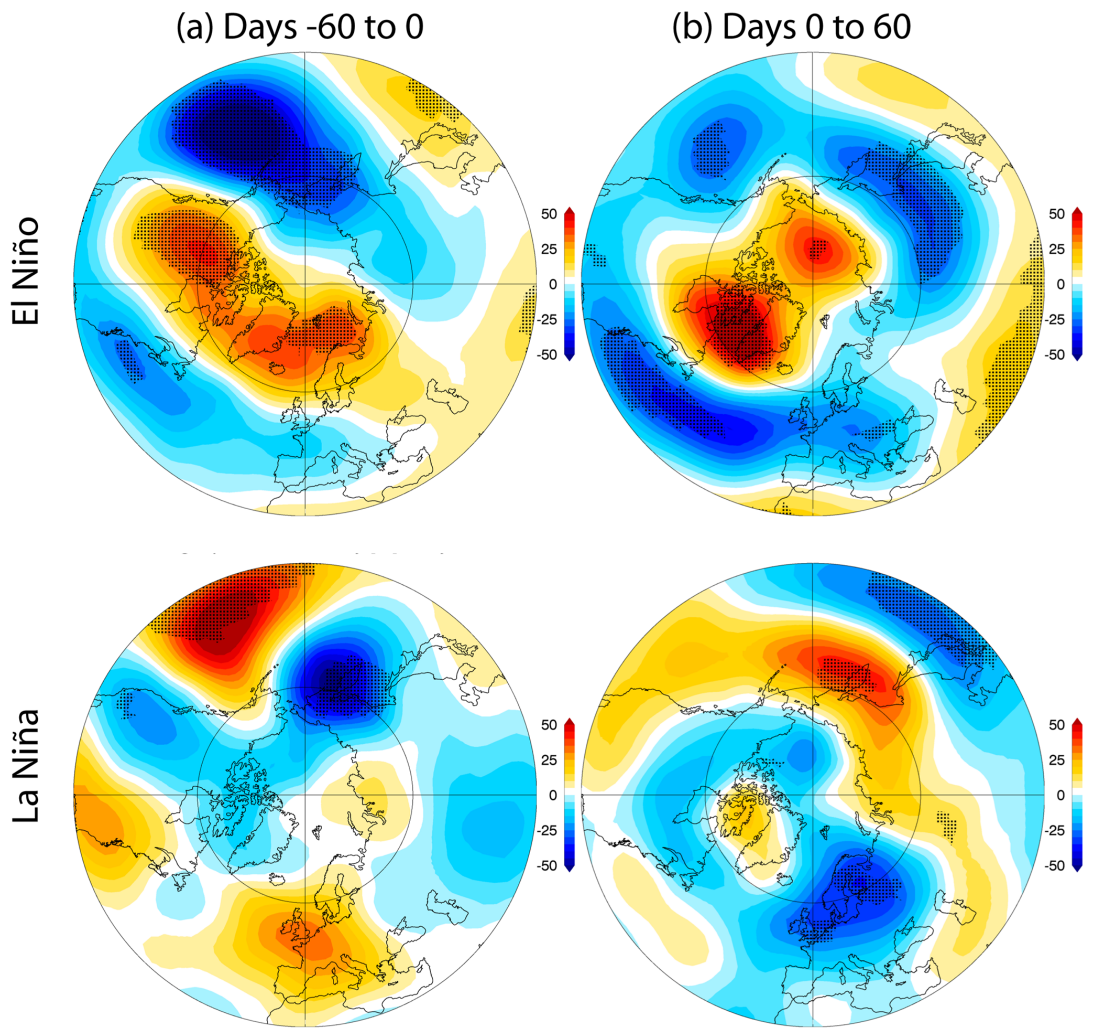

Figure 5. Composites of the $500 \mathrm{hPa}$ geopotential height anomalies (m) in JRA-55 reanalysis for (a) days -60 to 0 prior to historical SSWs and (b) days 0 to +60 after historical SSWs for (top row) El Niño winters and (bottom row) La Niña winters. The stippling indicates regions that are significantly different from the climatology at the $95 \%$ level. There are 13 events during El Niño winters and 9 events during La Niña winters. Here, if two SSWs occurred in one winter, we only considered the first event of the winter to avoid oversampling.

the 1985 event projects strongly onto the negative NAO pattern (Fig. 6c), with positive height anomalies over Greenland and negative height anomalies over the North Atlantic. This pattern is associated with much lower surface temperature anomalies over much of Europe and Asia. However, the height anomalies in the 2 months following the 2009 splittype event do not look like the negative NAO phase, though there are weakly positive height anomalies over the Arctic and two centers of low height anomalies over Europe and Asia (Fig. 6d). Temperature advection associated with these anomalous low-pressure centers may explain the regional cold air experienced over Asia and central Europe. Comparison of these two events shows how different modes of climate variability can impact the tropospheric climate during the period after a substantial SSW event. While 1985 and 2009 were both (essentially) La Niña winters (2009 misses 

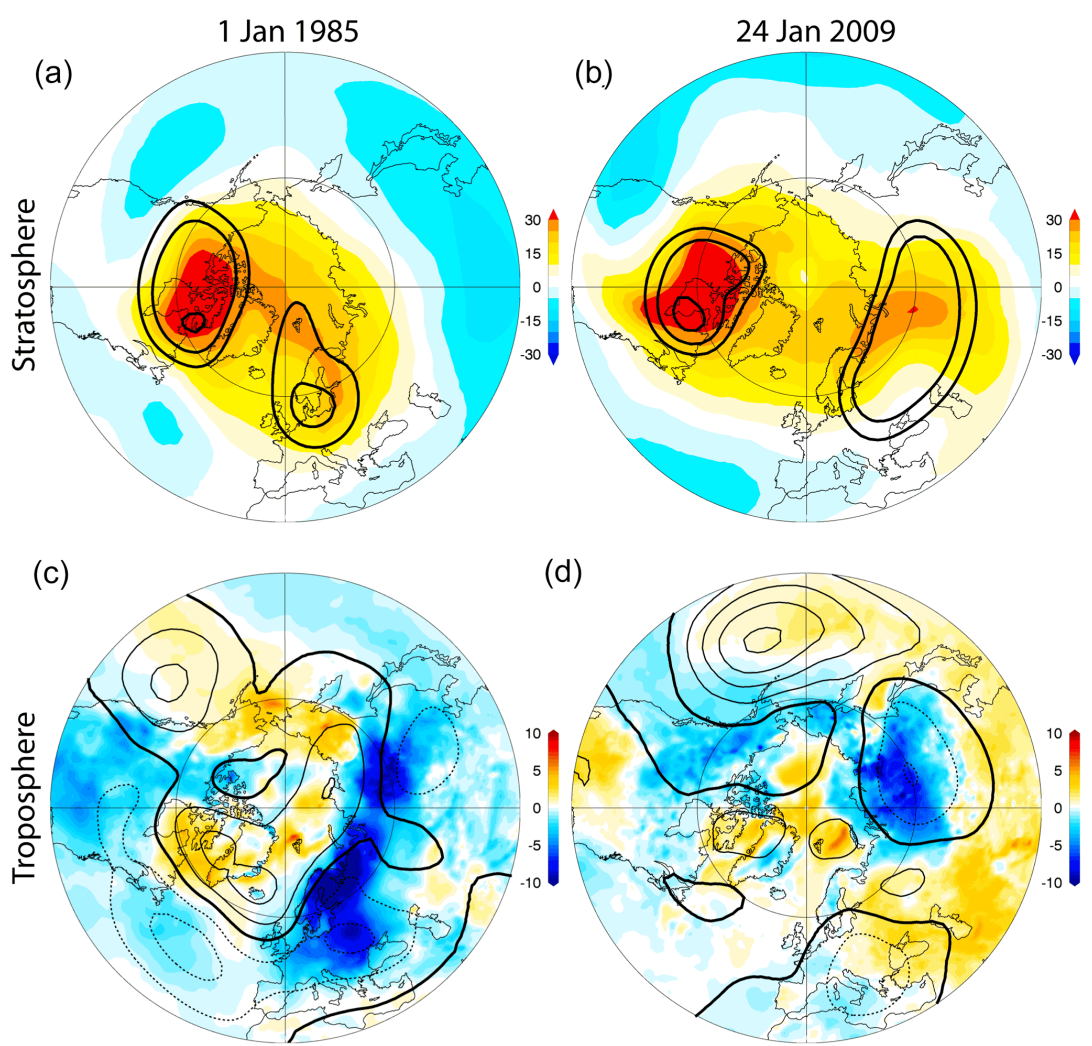

Figure 6. Comparison of two split-type SSW events, (a, c) 1 January 1985 and (b, d) 24 January 2009, for ERA-interim reanalysis. The top row (a, b) shows the $10 \mathrm{hPa}$ temperature anomalies (shading, $(\mathrm{K})$ ) and the potential vorticity at $550 \mathrm{~K}$ (contours shown for 75, 100, and $125 \mathrm{PV}$ units) at +4 days after the central date of the event. The bottom row $(\mathbf{c}, \mathbf{d})$ shows the surface temperature anomalies (shading, $(\mathrm{K})$ ) and the $500 \mathrm{hPa}$ geopotential height anomalies (contour interval is $50 \mathrm{~m}$, zero line is bold) averaged days $0-60$ after the central date of the event.

official La Niña classification by the NOAA Climate Prediction Center by $0.1^{\circ} \mathrm{C}$ ), the location and strength of the North Pacific ridge during these 2 years was quite different. Other aspects of climate variability, such as the QBO, sea ice, or the MJO, may have played a role in the tropospheric climate during these time periods.

The SSWC allows easy evaluation of the spread among individual events for different features of SSWs. Figure 7 shows time series of the (a) amplitude and (b) latitude of the maximum temperature anomaly (that occurs within the range of $30-90^{\circ}$ latitude and 300 to $1 \mathrm{hPa}$ ) and (c) the $200 \mathrm{hPa}$ $40-70^{\circ} \mathrm{N}$ eddy heat flux anomaly. On average, the maximum temperature anomaly of $\sim 50 \mathrm{~K}$ peaks $1-2$ days prior to the zonal wind reversal (Fig. 7a, bold black line), but the amplitude and timing vary substantially among the individual events (colored lines), with values from 10 to almost $100 \mathrm{~K}$. Likewise, the mean latitude where the temperature maximizes tends to fall between 60 and $70^{\circ} \mathrm{N}$ (Fig. 7b) but ranges from $\sim 45^{\circ} \mathrm{N}$ to the pole. The $200 \mathrm{hPa}$ heat flux anomaly represents the incoming heat fluxes from the troposphere via vertically propagating waves, which amplify and peak prior to the SSW (Polvani and Waugh, 2004; Sjoberg and Birner, 2014); however, during any individual year, there may be pulses of large heat fluxes that do not result in a SSW (Fig. 7c).

\subsection{Reanalysis intercomparison}

Finally, the SSWC includes data from six different reanalyses, both to aid in reanalysis intercomparison projects such as S-RIP and to allow users the ability to assess the robustness of SSW features in different products. Figure 8 demonstrates how these differences manifest during the January 2013 SSW event for (a) a modern reanalysis product (MERRA2), (b) an older reanalysis product with low model top (NCEP1), and (c) a reanalysis that only assimilates observations at the surface and has a strong bias in the stratosphere (NOAA20CR). In MERRA2, there is strong weakening of the zonal wind anomalies at $60^{\circ} \mathrm{N}$, which starts near $1 \mathrm{hPa}$ around the event date and descends over time to the tropopause (Fig. 8a, left panel). These anomalies are also evident in NCEP1, but output is only available up to $10 \mathrm{hPa}$, and the anomalies at $10 \mathrm{hPa}$ tend to be slightly smaller than those in MERRA2 (Fig. 8b). The NOAA20CRv2c makes an interesting comparison because the model stratospheric winds are too strong but the 

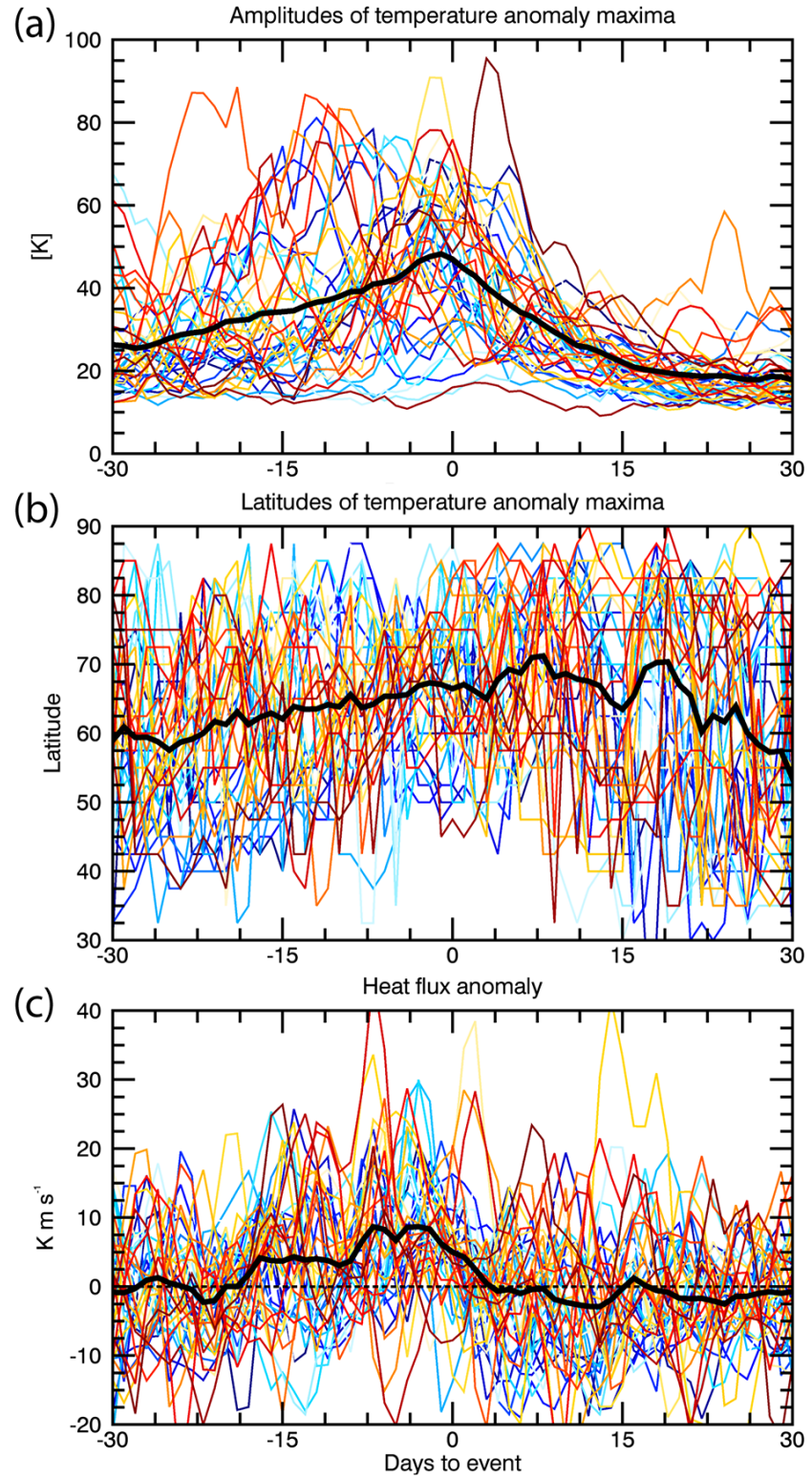

\section{Data usage and availability}

The SSWC is designed to be a public domain product that allows the user either to use the data as packaged or to step into the production process and regenerate parts of the database with customized configurations. A flowchart of these options is shown in Fig. 2. For example, if the user would like to use a different set of event dates or a different climatology, they may use the provided code and documentation to extract full fields from their reanalysis product of choice and to generate new anomaly and derived fields. Nonetheless, one major advantage of the SSWC is that both the full fields and the anomalies are provided (as well as the climatology), so that users can avoid downloading the terabytes of data needed to calculate the daily climatology and anomaly fields.

The SSW Compendium has been archived at NOAA's NCEI (doi:10.7289/V5NSORWP) in CF-compliant netCDF4 format. The data are compressed using short integer (16bit) packing, resulting in a full size of $300 \mathrm{~GB}$ for the SSWC. Some, but not all, programming platforms will properly read packed data and account for missing values. Care must be taken while reading packed data, or missing values may be unknowingly counted as finite data points.

A user's guide to the SSWC dataset is provided to describe the included variables and the file format. A production guide and source code in Interactive Data Language format are provided in case a user would like to recreate their own version of the SSWC. We anticipate future updates to the Compendium for those reanalysis products that proceed operationally in the future when new SSWs occur. When the Compendium is updated with a new SSW event, the climatologies and anomalies for all events will be updated, based on the full period of the new record. When publishing results based on the SSWC, users should clearly state what version and/or climatology is being used in order to allow reproducible results. 


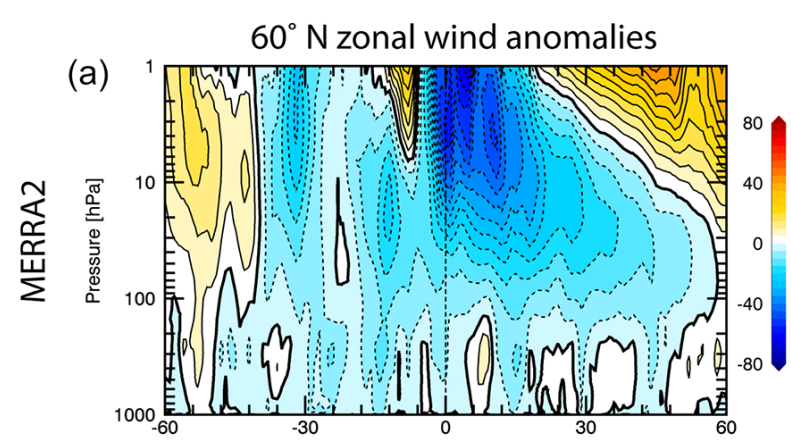

Tsfc \& $200 \mathrm{hPa}$ height anomaly
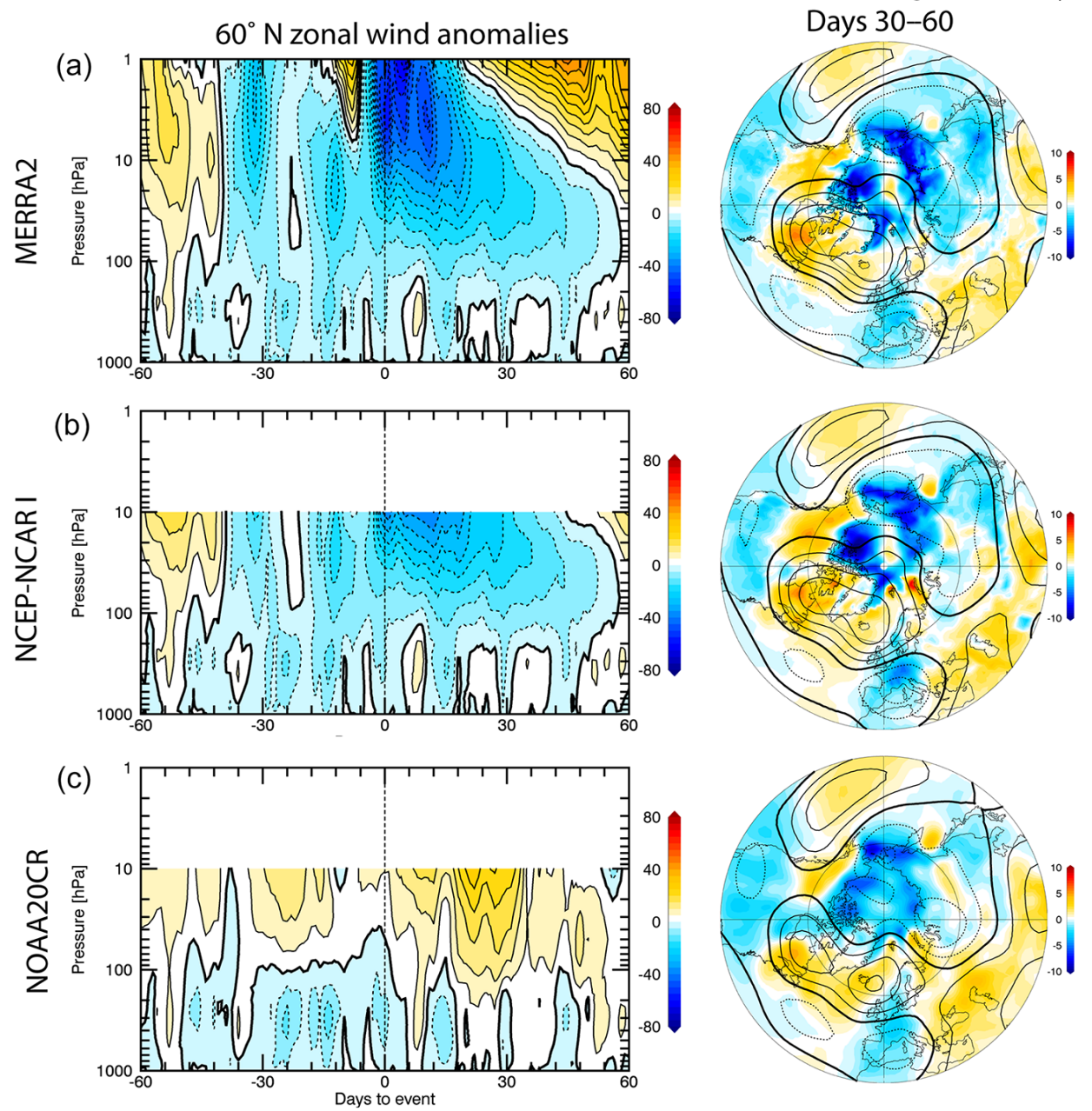

Figure 8. Comparison of three different reanalysis products for the 7 January 2013 SSW event: (a) MERRA2, (b) NCEP-NCAR I, and (c) NOAA20CR. The left column shows $60^{\circ} \mathrm{N}$ zonal-mean zonal wind anomalies $\left(\mathrm{m} \mathrm{s}^{-1}\right)$ as a function of time from the central date and pressure level. The right column shows the surface temperature anomalies (shading, $(\mathrm{K})$ ) and $200 \mathrm{hPa}$ geopotential height anomalies (contour interval is $50 \mathrm{~m}$ ) averaged over days 30-60 following the central date.

A subset of the SSWC can be plotted or animated at http: //www.esrl.noaa.gov/csd/groups/csd8/sswcompendium/.

The ability to readily perform (i) composite analysis, (ii) individual event analysis, and (iii) reanalysis intercomparison is one of the main goals of the SSW Compendium. The SSWC will hopefully allow users to highlight the role of stratosphere-troposphere processes and the importance of major SSW events in winter climate and provide a comprehensive database to compare with and improve model simulation of these events.

\section{Summary}

The SSWC database provides a simple and computationally inexpensive way to generate, download, and plot information on historical SSW events and their evolution and impacts on daily timescales. The database is designed to be used as is, but the end user also has the ability to use the source code to customize the database to meet their specific needs. The inclusion of six different reanalysis products and a set of full, anomaly, and derived fields for every major SSW in the historical record allows several different applications of the SSWC. The ability to readily perform (i) composite analysis, (ii) individual event analysis, and (iii) reanalysis intercomparison for projects such as S-RIP will hopefully allow users to highlight the role of stratosphere-troposphere processes and the importance of major SSW events in winter climate and provide a comprehensive database to compare with and improve model simulation of these events.

Competing interests. The authors declare that they have no conflict of interest. 
Acknowledgements. This work was funded by the NOAA Climate Program Office.

Edited by: G. König-Langlo

Reviewed by: W. Seviour and one anonymous referee

\section{References}

Baldwin, M. P. and Dunkerton, T. J.: Stratospheric Harbingers of Anomalous Weather Regimes, Science, 294, 581-584, doi:10.1126/science.1063315, 2001.

Baldwin, M. P. and Thompson, D. W. J.: A critical comparison of stratosphere-troposphere coupling indices, Q. J. Roy. Meteor. Soc., 135, 1661-1672, doi:10.1002/qj.479, 2009.

Baldwin, M. P., Gray, L. J., Dunkerton, T. J., Hamilton, K., Haynes, P. H., Randel, W. J., Holton, J. R., Alexander, M. J., Hirota, I., Horinouchi, T., Jones, D. B. A., Kinnersley, J. S., Marquardt, C., Sato, K., and Takahashi, M.: The quasi-biennial oscillation, Rev. Geophys., 39, 179-229, doi:10.1029/1999RG000073, 2001.

Bosilovich, M. G., Chen, J., Robertson, F. R., and Adler, R. F.: Evaluation of Global Precipitation in Reanalyses, J. Appl. Meteorol. Clim., 47, 2279-2299, doi:10.1175/2008JAMC1921.1, 2008.

Butler, A. H. and Polvani, L. M.: El Niño, La Niña, and stratospheric sudden warmings: A reevaluation in light of the observational record, Geophys. Res. Lett., 38, L13807, doi:10.1029/2011GL048084, 2011.

Butler, A. H., Polvani, L. M., and Deser, C.: Separating the stratospheric and tropospheric pathways of El Niño-Southern Oscillation teleconnections, Environ. Res. Lett., 9, 024014, doi:10.1088/1748-9326/9/2/024014, 2014.

Butler, A. H., Seidel, D. J., Hardiman, S. C., Butchart, N., Birner, T., and Match, A.: Defining Sudden Stratospheric Warmings, B. Am. Meteorol. Soc., 96, 1913-1928, doi:10.1175/BAMS-D-1300173.1, 2015.

Butler, A. H., Sjoberg, J., Seidel, D. J., and NOAA ESRL Chemical Science Division: Sudden Stratospheric Warming Compendium, Version 1.0, NOAA National Centers for Environmental Information (NCEI), doi:10.7289/V5NSORWP, 2016.

Charlton, A. J. and Polvani, L. M.: A new look at stratospheric sudden warmings. Part I: Climatology and modeling benchmarks, J. Climate, 20, 449-469, 2007.

Compo, G. P., Whitaker, J. S., Sardeshmukh, P. D., Matsui, N., Allan, R. J., Yin, X., Gleason, B. E., Vose, R. S., Rutledge, G., Bessemoulin, P., Brönnimann, S., Brunet, M., Crouthamel, R. I., Grant, A. N., Groisman, P. Y., Jones, P. D., Kruk, M. C., Kruger, A. C., Marshall, G. J., Maugeri, M., Mok, H. Y., Nordli, Ø., Ross, T. F., Trigo, R. M., Wang, X. L., Woodruff, S. D., and Worley, S. J.: The Twentieth Century Reanalysis Project, Q. J. Roy. Meteor. Soc., 137, 1-28, doi:10.1002/qj.776, 2011.

Dee, D. P., Uppala, S. M., Simmons, A. J., Berrisford, P., Poli, P., Kobayashi, S., Andrae, U., Balmaseda, M. A., Balsamo, G., Bauer, P., Bechtold, P., Beljaars, A. C. M., van de Berg, L., Bidlot, J., Bormann, N., Delsol, C., Dragani, R., Fuentes, M., Geer, A. J., Haimberger, L., Healy, S. B., Hersbach, H., Hólm, E. V., Isaksen, L., Kållberg, P., Köhler, M., Matricardi, M., McNally, A. P., Monge-Sanz, B. M., Morcrette, J.-J., Park, B.-K., Peubey, C., de Rosnay, P., Tavolato, C., Thépaut, J.-N., and Vitart, F.: The ERA-Interim reanalysis: configuration and performance of the data assimilation system, Q. J. Roy. Meteor. Soc., 137, 553-597, doi:10.1002/qj.828, 2011.

Dethof, A. and Hólm, E. V: Ozone assimilation in the ERA-40 reanalysis project, Q. J. Roy. Meteor. Soc., 130, 2851-2872, doi:10.1256/qj.03.196, 2004.

Dragani, R.: On the quality of the ERA-Interim ozone reanalyses: comparisons with satellite data, Q. J. Roy. Meteor. Soc., 137, 1312-1326, doi:10.1002/qj.821, 2011.

Dunkerton, T., Delisi, D., and Baldwin, M.: Distribution of Major Stratospheric Warmings in Relation to the QuasiBiennial Oscillation, Geophys. Res. Lett., 15, 136-139, doi:10.1029/GL015i002p00136, 1988.

Fujiwara, M., Wright, J. S., Manney, G. L., Gray, L. J., Anstey, J., Birner, T., Davis, S., Gerber, E. P., Harvey, V. L., Hegglin, M. I., Homeyer, C. R., Knox, J. A., Krüger, K., Lambert, A., Long, C. S., Martineau, P., Monge-Sanz, B. M., Santee, M. L., Tegtmeier, S., Chabrillat, S., Tan, D. G. H., Jackson, D. R., Polavarapu, S., Compo, G. P., Dragani, R., Ebisuzaki, W., Harada, Y., Kobayashi, C., McCarty, W., Onogi, K., Pawson, S., Simmons, A., Wargan, K., Whitaker, J. S., and Zou, C.-Z.: Introduction to the SPARC Reanalysis Intercomparison Project (S-RIP) and overview of the reanalysis systems, Atmos. Chem. Phys. Discuss., doi:10.5194/acp-2016-652, in review, 2016.

Garfinkel, C. I., Butler, a. H., Waugh, D. W., Hurwitz, M. M., and Polvani, L. M.: Why might stratospheric sudden warmings occur with similar frequency in El Niño and La Niña winters?, J. Geophys. Res. Atmos., 117, D19106, doi:10.1029/2012JD017777, 2012.

Garfinkel, C. I., Benedict, J. J., and Maloney, E. D.: Impact of the MJO on the boreal winter extratropical circulation, Geophys. Res. Lett., 41, 6055-6062, doi:10.1002/2014GL061094, 2014.

Gerber, E. P., Butler, A., Calvo, N., Charlton-Perez, A., Giorgetta, M., Manzini, E., Perlwitz, J., Polvani, L. M., Sassi, F., Scaife, A. A., Shaw, T. A., Son, S.-W., and Watanabe, S.: Assessing and Understanding the Impact of Stratospheric Dynamics and Variability on the Earth System, B. Am. Meteorol. Soc., 93, 845-859, doi:10.1175/BAMS-D-11-00145.1, 2012.

Gómez-Escolar, M., Calvo, N., Barriopedro, D., and Fueglistaler, S.: Tropical response to stratospheric sudden warmings and its modulation by the QBO, J. Geophys. Res.-Atmos., 119, 73827395, doi:10.1002/2013JD020560, 2014.

Hoffmann, P., Singer, W., Keuer, D., Hocking, W. K., Kunze, M., and Murayama, Y.: Latitudinal and longitudinal variability of mesospheric winds and temperatures during stratospheric warming events, J. Atmos. Sol.-Terr. Phys., 69, 2355-2366, doi:10.1016/j.jastp.2007.06.010, 2007.

Kalnay, E., Kanamitsu, M., Kistler, R., Collins, W., Deaven, D., Gandin, L., Iredell, M., Saha, S., White, G., Woollen, J., Zhu, Y., Chelliah, M., Ebisuzaki, W., Higgins, W., Janowiak, J., Mo, K. C., Ropelewski, C., Wang, J., Leetmaa, A., Reynolds, R., Jenne, R., and Joseph, D.: The NCEP/NCAR 40-year reanalysis project, B. Am. Meteorol. Soc., 77, 437-471, 1996.

Kidston, J., Scaife, A. A., Hardiman, S. C., Mitchell, D. M., Butchart, N., Baldwin, M. P., and Gray, L. J.: Stratospheric influence on tropospheric jet streams, storm tracks and surface weather, Nat. Geosci., 8, 433-440 doi:10.1038/ngeo2424, 2015.

Kobayashi, S., Ota, Y., Harada, Y., Ebita, A., Moriya, M., Onoda, H., Onogi, K., Kamahori, H., Kobayashi, C., Endo, H., Miyaoka, K., and Takahashi, K.: The JRA-55 Reanalysis: General Spec- 
ifications and Basic Characteristics, J. Meteorol. Soc. Jpn., 93, 5-48, doi:10.2151/jmsj.2015-001, 2015.

Kodera, K.: Influence of stratospheric sudden warming on the equatorial troposphere, Geophys. Res. Lett., 33, L06804, doi:10.1029/2005GL024510, 2006.

Kruger, K., Naujokat, B., and Labitzke, K.: The Unusual Midwinter Warming in the Southern Hemisphere Stratosphere 2002, J. Atmos. Sci., 62, 603-613, 2005.

Labitzke, K. and Collaborators: The Berlin Stratospheric Data Series, CD from Meteorol. Institute, Free Univ. Berlin, 2002.

Labitzke, K. and Kunze, M.: Stratospheric temperatures over the Arctic: Comparison of three data sets, Meteorol. Z., 14, 65-74, doi:10.1127/0941-2948/2005/0014-0065, 2005.

Labitzke, K., Kunze, M., and Brönnimann, S.: Sunspots, the QBO and the stratosphere in the North Polar Region - 20 years later, Meteorol. Z., 15, 355-363, doi:10.1127/0941-2948/2006/0136, 2006.

Manney, G. L., Sabutis, J. L., Pawson, S., Santee, M. L., Naujokat, B., Swinbank, R., Gelman, M. E., and Ebisuzaki, W.: Lower stratospheric temperature differences between meteorological analyses in two cold Arctic winters and their impact on polar processing studies, J. Geophys. Res.-Atmos., 108, 8328, doi:10.1029/2001JD001149, 2003.

Manney, G. L., Schwartz, M. J., Krüger, K., Santee, M. L., Pawson, S., Lee, J. N., Daffer, W. H., Fuller, R. A., and Livesey, N. J.: Aura Microwave Limb Sounder observations of dynamics and transport during the record-breaking 2009 Arctic stratospheric major warming, Geophys. Res. Lett., 36, L12815, doi:10.1029/2009GL038586, 2009.

Martineau, P. and Son, S.-W.: Quality of reanalysis data during stratospheric vortex weakening and intensification events, Geophys. Res. Lett., 37, L22801, doi:10.1029/2010GL045237, 2010.

Martineau, P., Son, S.-W., and Taguchi, M.: Dynamical consistency of reanalysis data sets in the extratropical stratosphere, J. Climate, 29, 3057-3074, doi:10.1175/JCLI-D-15-0469.1, 2016.

Maycock, A. C. and Hitchcock, P.: Do split and displacement sudden stratospheric warmings have different annular mode signatures?, Geophys. Res. Lett., 42, 10910-943951, doi:10.1002/2015GL066754, 2015.

Mitchell, D. M., Charlton-Perez, A. J., and Gray, L. J.: Characterizing the Variability and Extremes of the Stratospheric Polar Vortices Using 2D Moment Analysis, J. Atmos. Sci., 68, 1194-1213, doi:10.1175/2010JAS3555.1, 2011.

Molod, A., Takacs, L., Suarez, M., and Bacmeister, J.: Development of the GEOS-5 atmospheric general circulation model: evolution from MERRA to MERRA2, Geosci. Model Dev., 8, 1339-1356, doi:10.5194/gmd-8-1339-2015, 2015.

Newman, P. A. and Rosenfield, J. E.: Stratospheric thermal damping times, Geophys. Res. Lett., 24, 433-436, doi:10.1029/96GL03720, 1997.

Palmeiro, F. M., Barriopedro, D., García-Herrera, R., and Calvo, N.: Comparing Sudden Stratospheric Warming Definitions in Reanalysis Data, J. Climate, 28, 6823-6840, doi:10.1175/JCLI-D15-0004.1, 2015.
Polvani, L. M. and Waugh, D. W.: Upward Wave Activity Flux as a Precursor to Extreme Stratospheric Events and Subsequent Anomalous Surface Weather Regimes, J. Climate, 17, 3548-3554, doi:10.1175/15200442(2004)017<3548:UWAFAA>2.0.CO;2, 2004.

Richter, J., Deser, C., and Sun, L.: Effects of stratospheric variability on El Niño teleconnections, Environ. Res. Lett., 10, 124021, doi:10.1088/1748-9326/10/12/124021, 2015.

Schoeberl, M. R.: Stratospheric warmings: Observations and theory, Rev. Geophys., 16, 521, doi:10.1029/RG016i004p00521, 1978.

Schoeberl, M. R. and Hartmann, D. L.: The Dynamics of the Stratospheric Polar Vortex and Its Relation to Springtime Ozone Depletions, Science, 251, 46-52, doi:10.1126/science.251.4989.46, 1991.

Seviour, W. J. M., Mitchell, D. M., and Gray, L. J.: A practical method to identify displaced and split stratospheric polar vortex events, Geophys. Res. Lett., 40, 5268-5273, doi:10.1002/grl.50927, 2013.

Sjoberg, J. P. and Birner, T.: Stratospheric wave-mean flow feedbacks and sudden stratospheric warmings in a simple model forced by upward wave-activity flux, J. Atmos. Sci., 71, 40554071, doi:10.1175/JAS-D-14-0113.1, 2014.

Thompson, D. W. J., Wallace, J. M., and Hegerl, G. C.: Annular Modes in the Extratropical Circulation. Part II: Trends, J. Climate, 13, 1018-1036, doi:10.1175/1520-0442(2000)013< 1018:AMITEC>2.0.CO;2, 2000.

Uppala, S., Kallberg, P., Simmons, A., Andrae, U., Bechtold, V., Fiorino, M., Gibson, J., Haseler, J., Hernandez, A., Kelly, G., Li, X., Onogi, K., Saarinen, S., Sokka, N., Allan, R., Andersson, E., Arpe, K., Balmaseda, M., Beljaars, A., Van De Berg, L., Bidlot, J., Bormann, N., Caires, S., Chevallier, F., Dethof, A., Dragosavac, M., Fisher, M., Fuentes, M., Hagemann, S., Holm, E., Hoskins, B., Isaksen, L., Janssen, P., Jenne, R., McNally, A., Mahfouf, J., Morcrette, J., Rayner, N., Saunders, R., Simon, P., Sterl, A., Trenberth, K., Untch, A., Vasiljevic, D., Viterbo, P., and Woollen, J.: The ERA-40 re-analysis, Q. J. Roy. Meteor. Soc., 131, 2961-3012, doi:10.1256/qj.04.176, 2005.

Van Loon, H., Jenne, R. L., and Labitzke, K.: Zonal harmonic standing waves, J. Geophys. Res., 78, 4463-4471, doi:10.1029/JC078i021p04463, 1973.

Waugh, D. N. W.: Elliptical diagnostics of stratospheric polar vortices, Q. J. Roy. Meteor. Soc., 123, 1725-1748, doi:10.1002/qj.49712354213, 1997.

Wilks, D. S.: Statistical Methods in the Atmospheric Sciences, 2nd Edn., Academic Press, London, 2006.

Zhang, X., Hegerl, G., Zwiers, F. W., and Kenyon, J.: Avoiding Inhomogeneity in Percentile-Based Indices of Temperature Extremes, J. Climate, 18, 1641-1651, doi:10.1175/JCLI3366.1, 2005 . 